\title{
NA-BASIESE VERPLEEGSTUDENTE SE PERSEPSIES VAN DIE VAK ETOS VAN VERPLEGING
}

\author{
H Kirstein
}

\section{OPSOMMING}

in Verpleegkundige se strewe na professionalisme is van kardinate belang by die uitvoer van haar praktyk. Mel hierdie navorsing is bepaal wal na-basiese verpleegstudente se persepsies van die vak Etos van Verpleging is nadat hulle reeds eksamen in die vak afgele het. Die doel hienvan was om vas te stel in hoe 'n mate die student strewe na professionalisme, aangesien die student se persepsies van Etos sinoniem is met haar houding teenoor professionalisme.

Tydens die student se basiese opleiding in verpleegkunde onsvang sy onderrig in die grondbeginsels van die vak Etos en daar is met hierdie navorsing vasgestel dat hierdie basiese onderrig nie in alle opsigte voldoen aan die vereistes wat aan 'n verpleegluundige gestel word nadat sy geregistreer het nie. Die verpleegstudente in hul basiese opleiding is oorwegend nog jong adolessente en ervaar die vak Etos dikwels negatief. Uit die antleding van die data het dit geblyk dat die studente se persepsies tydens hulle studies by Unisa van negatief na positief verander het. Dit bevestig dan die aanname dat die vak Etos en die impak wat dit op die verpleegpraktisyn se strewe na professionalisme maak, eers volle potensiaal bereik op na-basiese vlak.

\section{ABSTRACT}

The registered nurse's pursuit of professionalism is of prime importance in the execution of her losk. This research attempts to assess the perceptions concerning the subject Ethos of Nursing held by post-registration mursing students - after they had written the examination on the subject. The purpose was to determine the extent of the student's pursuit of professionalism, as her perception of Ethos is symonymous with her attitude towards professionalism.

During the student's basic education in Nursing Science she was taught the fundamental principles of Ethos. This research revealed that this basic teaching failed to meet the requirements of the nurse subsequent to registration. It appeared that the students 'perceptions changed from negative to positive during their studies at Unisa. This finding supported the assumption that the subject Ethos, and its impact on the nurse practitioner's pursuit of professionalism, might only reach its full potential at the post-basic level.

Etos van Verpleging en Verloskunde (Etos in kort) asook die belang van die studie.

Die vak etos plaas die aard en filosofie van verpleging, verpleegteoriec, die geskiedenis van verpleging, professionele praktyk asook etiek en wette in perspektief ten einde die verpleegkundige praktisyn toe te rus met ' $n$ hegeerte om as rolmodel op te tree in has diens aan die mensdom. Die strewe na professionalisme werk as motivering in op die verpleegkundige praktisyn. Hierdie motiveringskrag vorm nie net haar professionaliteil nie, mar ook haar lewensbeskouing. In die professie is daar steeds ' $n$ gekonsentreerde strewe na professionalisme. Dit word bespreek en annemoedig in literatuur, by simposia en deur die beheerliggame van die professie.

Ongelukkig word hierdie strewe na professionalisme nie altyd deurgevoer tot op grondvlak was daar met menselewens gewerk word nie. Dit gebeur dan dat die konkrete onderrig wat elke studentverpleegkundige aangande die Etos van Verpleging moet ontvang ten einde hasr bedag op en vertroud te maak met die kriteria vir professionalisme, agterwee bly. Die ondersoekkomitee van die Suid-Afrikaanse Raad op Verpleging hoor klagtes aan oor beweerde wangedrag van verpleegkundiges en vroedvroue en daar moet prima facie-bewys van professionele wangedrag gevind word. Male sonder tal word dit tydens hierdie sittings duidelik dat baie verpleegpraktisyns en verloskundiges die professionele praktykbeginsels sowel as die etiese kode van die beroep oortree as gevolg van onkunde en/of ' $n$ gebrekkige besef van die hoe standaard wat van has as professionele verpleegkundige vereis word.

Verder het dit deur die jare duidelik geword dat daar ' $n$ leemte bestaan in die onderrig van professionele praktykbeginsels met inbegrip van die geregtelike en etiese dimensies daarvan. (Searle 1987a: Voorwoord). Etos in totaliteit word egter deur hierdic leemte geraak.

Professionalisme sluit ' $n$ persoonlike belofte en verpligting sowel as " $n$ gesamentlike verpligting deur professionele praktisyns as ' $n$ sosiale groep in. Hierdie belofte word in effek aan die gemeenskap gemaak en word dan ' $n$ etiese saak. Die individu wat die belofte gemaak het, het ' $n$ plig om op te tree en dié aan wie die belofte gemaak is het ' $n$ reg op dit wat belowe is. Dit is ' $n$ onweerlegbare feit dat regte en pligle die individu by etiek betrek. Dit is dan wasom professionele aangeleenthede ook etiese anngeleenthode is. Professionele aangeleenthede het direk te make met die professie se vermot om die belofte wat aan die gemeenskap gemaak is, gestand te doen (Quinn \& Smith 1987: 3).

Conway-Welch in Chaska (1990: 572), noem die feit dat die professionele verpleegkundige wat vandag gevorm en ontwikkel word, nie waardering het vir onder andere geskiedenis en filosofie nie. Ten spyte hiervan kom die verpleegkundige in ' $n$ toenemende mate in aanraking met gekompliseerde morele en tegniese aspekte, wat veroorsask dat hulle hulself en hul waardesisteme voortdurend ondersoek (Chaska 1990: 572).

Indien die verpleegkundige nie deeglik onderlè word in geskiedenis, filosofie, teoriet en etiek nie, sal hierdie morele en tegniese aspekte nie op ' $n$ professionele manier hanteer kan word nie. In die belang van die student se persepsies van Etos sal die gehalte van die na-registrasie verpleegstudent as professionele praktisyn voor-die-handliggend wees, aangesien Etos soos reeds genoem, sinoniem is met professionaliteit. 
Deur die na-basiese geregistreerde verpleegkundige se persepsies van die vak Etos te monitor, kan daar konkrete en wasdevolle afleidings gemaak word aangaande die professionaliteit van hierdie parktisyn en hoe belangrik sy professionaliteit beskou. Laasgenoemde afleiding is belangrik aangesien daar so maklik deur ' $n$ geregistreerde verpleegkundige aanvaar word dat sy ' $n$ professionele persoon is sonder dat sy werklik bewus is van die betekenis en implikasies van professionalisme. Haar vlak van kundigheid word met ander woorde ten opsigte van die cise wat aan haar gestel word, bevraagteken. ' $n$ Belangrike oogmerk van hierdie studie was reeds om veral die knelpunte wat die verpleegkundige rem in haar professionele optrede, te identifiseer. Die toenemende aantal geregistreerde verpleegkundiges wat onderwerp word aan die Suid-Afrikaanse Raad op Verpleging se dissiplincere optrede, is kommerwekkend.

\section{DOEL VAN DIE STUDIE}

Met hierdie studie is beoog om:

1) die student se siening oor die belangrikheid van haar kennis en insig in die vak Etos' vir haar geloofwardigheid as professionele geregistreerde verplecgkundige, te peil

2) die faktore wat in die student se skolastiese en akademiese verlede moontlik asnleiding kon gegee het tot ' $n$ aanvanklike gebrekkige insig in die noodsaaklikheid van die vak, te identifiseer

3) die student se houding teenoor die eise wat haar beroep aan haar as professionele praktisyn buite werkverband stel, te bepaal

Hierdie navorsing sluit die skoolvlak in en strek oor die wye akademiese spektrum tot en met die student se studies by die Universiteit van Suid-Afrika.

\section{NAVORSINGSMETODES:}

Toegepaste navorsing is as metode gebruik ten einde

- persepsies te evalueer

- behoeftebepalings te doen

- oplossings te vind vir probleme

- besluite ter verbetering te neem (Seaman 1987: 3)

Die beskrywende oprame metode is gebruik aangesien hierdie ontwerp die meet van veranderlikes deur die toetsing van hul verwantskap dikteer. Met hierdie navorsing is 'n steekproef gedoen van na-registrasieverpleegkundiges wat noodwendig oor verskillende tipes opvoedkundige agtergronde beskik. Genoemde agtergronde is tydens die analisering van data vergelyk met die respondent se persepsies van die vak Etos. Die doel hiervan was om vas te stel in hoe ' $n$ mate die respondente se persepsies met hul opvoedkundige agtergrond en vlak asook ervarings korreleer (Brink \& Wood 1988: 103).

Daar is van die verkennende navorsingsmetode gebruik gemaak aangesien die veranderlikes nog nie in hierdie spesifieke populasie, namlik na-registrasie Unisa-verpleegstudente, getoets is nie.

Die waarneming wat tydens hierdie navorsing gedoen is, kan as kwantitatiewe waarneming geklassifiseer word, aangesien dit objektiverend is, waarnemings vooraf beplan is (in hierdie geval deur middel van die vraelys), die navorser afsydig gebly het, sommige waarnemings skaleerbaar was, verwagte waarnemings gekategoriseer is en die konteks sover moontlik gekontroleer is.

\section{TEIKENGROEP}

Hierdie navorsing het na-registrasieverpleegstudente betrek en het tot gevolg gehad dat die teikengroep uit Unisa-studente geselekteer is. Alle studente by die Departement Verpleegkunde aan Unisa moet vir Etos 1 registreer aangesien dit ' $n$ verpligte vak is. Dit was vir die navorser verder belangrik dat die teikengroep hul persepsies van die vak Etos nog duidelik kan herroep. Geheue-afname is ' $n$ subjekeienskap (subjek/respondent) en Smith in Mouton en Marais (1989: 87) sê dat die navorser ' $n$ afname in die vermot om gebeure te onthou. moet aanvaar.

' $n$ Verdere punt van belang wat in gedagte gehou is, is die feit dat die studente se persepsies van die vak hier van belang was. Studente wat hul studies gestaak het gedurende 1989 kon nie ingesluit word nie Die fmale teikengroep het dus bestaan uit na-registrasieverpleegstudente wat eksamen afgelê het in die vak Etos van Verpleging en Professionele Praktyk I (Etos 1) in 1989, ongeag of hulle die eksamen geslaag het al dan nie $(\mathrm{N}=2323)$

\section{STEEKPROEFTREKKING}

Om voordeel plus partydigheid uit te skakel is daar van 'n ewekansige steekproeftrekking gebruik gemaak. Die gemeenskaplike kenmerk van die groep wat ' $n$ vereiste by hierdie metode is, was die feit dat al die persone in die teikengroep na-registrasie verpleegkundiges was wat reeds in 1989 eksamen in die vak Etos by Unisa afgelê het

\section{NAVORSINGSINSTRUMENT EN SKALE}

Vanweè die wye geografiese verspreiding van die respondente, is daar op ' $n$ vraelys besluit. Daar is 612 vraelyste landwyd gepos vanuit ' $n$ totale steekproef van 2323 na-registrasie verpleegkundiges wat reeds eksamen in die vak Etos by Unisa afgele het. Die gestruktureerde vraelys is ontwerp na ' $n$ intensiewe en uitgebreide literatuurstudie.

Die vraelys bet uit die volgende afdelings bestaan:

AFDELING 1: Inligting is verkry wat op die respondent se skoolopleiding betrekking gehad het. ' $n$ Belangrike aspek in hierdie afdeling was of die respondent geskiedenis as vak op skool gehad het of nie. Dit het duidelik in die literatuurstudie na vore gekom dat daar op cerstejaarsvlak tydens basiese opleiding nie rekening gehou word met studente wat nie geskiedenis as vak op skool gehad het nie. Hier is veral van die nominale skaal gebruik gemaak.

AFDELING 2: Die inligting het betrekking gehad op die respondent se basiese opleiding in verpleging. Hier is veral vasgestel hoeveel lesings, indien enige, daar in Etos ontvang is en die verspreiding van die lesings oor die hele kursus. Die respondente moes hier onderskei tussen professionele praktyk wat onder andere ook die rexls en regulasies insluit, ' $n$ filosofie van verpleging, verpleegteoriec, die geskiedenis van verpleging en etiek. Daar is in hierdie afdeling ook vasgestel of die respondent na afloop van haar basiese opleiding ten volle voorberei was op haar rol as professionele verpleegkundige. Hier is van ' $n$ ordinale skaal en wel die grafiese merieteskaal gebruik gemaak.

AFDELING 3: Die afdeling bestaan uit vrae rakende die respondent se studies by Unisa. Faktore wat betrekking het op Unisa en wat die student ook positief of negatief kon beïnvloed ten opsigte van Etos, is deur middel van hierdie afdeling gelsoleer. Hier is ook, soos by Afdeling 2 van ' $n$ grafiese merieteskaal gebruik gemaak.

AFDELING 4: Vrae rakende die student se professionele status is in afdeling 4 vervat. As geregistreerde verpleegkundige geniet sy professionele status en dit hou verband met haar professionele houding, optrede, oortuigings en gedrag. Kennis en insig aangaande professionaliteit word hier verlang.

In afdeling 4 is daar ' $n$ groep items wat betrekking het op die graad van professionaliteit van die praktisyn en wat sig uitstekend leen tot die gebruik van 'n Likertskaal, wat 'n kragtige meetinstrument is vir onder andere persepsies en houdings Hierdie skaal is ' $n$ baie gewilde skaal by verpleegnavorsing en is by genoemde groep items gekombineer met die Guttmanskaal. Die Guttmanskaal is gebruik waar stellings gemask word wat op mekaar betrekking het Die respondent moet byvoorbeeld met stellings 2 en 3 saamstem as sy met stelling 1 saamgestem het, masr nie noodwendig met stelling 4 nie (Seaman 1987: 306-310).

AFDELING 5: Vrae rakende eise wat die professionele verpleegkundige se beroep aan haar stel is in afdeling 5 ingesluit. Dit is ' $n$ kort 
afdeling en daar is bloot gepoog om vas te stel tot hoe ' $\mathrm{n}$ mate die respondent betrokke is by haar beroep. In hierdie afdeling is daar weer hoofanklik van 'n ordinale skaal gebruik gemank.

AFDELING 6: Demografiese inligting is in hierdie afdeling verksy. Seaman (1987: 283) sê "... many researchers prefer to end the questionnaire with these questions because they tend to be routine and somewhat dull". Hierdie afdeling is dan heel laaste geplass ten einde te voorkom dat verveeldheid reeds aan die begin van die vraelys voorkom, en daar is hoofsaklik van 'n nominale skaal gebruik gemak.

\section{GELDIGHEID EN BETROUBAARHEID}

Konstrukgeldigheid van die instrument is bepaal deur die reaksie van die respondente wat aan die voortoets deelgeneem het. Geen konstrukveranderings is aangebring na aanleiding van die geanaliseerde data van die voortoets nie. Die betroubsarheid van die instrument is gemeet aan die interpretasie van die respondente. Die verskillende items is deurgaans eenders geinterpreteer aangesien dasi geen antwoorde voorgekom het wat op verwarring gedui het nie.

\section{INSAMELING EN VERWERKANG VAN DATA}

In total is 612 vraelyste versend. Na die sperdatum is 416 terugontvangde (bruikbare) vraelyste gekodeer en geanaliseer (Tabel 1). Met die hulp van 'n rekenasprogrammeerder is ' $n$ program opgestel met die nodige instruksies om vrae oor en weer te vergelyk, in verband te bring met mekaar en te korreleer. Data is deur middel van die rekenaar verwerk volgens die SAS-gteleel (Statistical Analysis Systems).

\begin{tabular}{|c|c|c|}
\hline $\begin{array}{l}\text { TABEL } 1 \\
\text { VRAELYST }\end{array}$ & $\begin{array}{l}\text { ESPONS OF } \\
\text { WAT AAN S } \\
\text { GEPOS IS }\end{array}$ & $\begin{array}{l}\text { DIE } 612 \\
\text { TUDENTE }\end{array}$ \\
\hline Vrachyote & Hoeveelheid & Persentasio \\
\hline Terug ontvang & 416 & 68 \\
\hline $\begin{array}{l}\text { Nie torug } \\
\text { ontvang niv }\end{array}$ & 171 & 28 \\
\hline Onbruikbaar & 25 & 4 \\
\hline TOTAAL & 612 & 100 \\
\hline
\end{tabular}

\section{GEVOLGTREKKINGS}

\section{AFDELING 1: Skoolopleiding}

Die meeste respondente het met ' $n$ st. 10-sertifikant hul basiese verpleegopleiding begin. Sewentig persent van die respondente hel geskiedenis op skool gehad en dus was verpleeggeskiedenis as leervak nie vir hulle 'n vreemde ervaring nie, maar slegs $53.8 \%$ het die vak uit vrye keuse geneem Verpleegstudente wat nie geskiedenis as vak

TABEL 2 ASPEKTE RAKENDE DIE RESPONDENT SE LOOPBAAN AS PROFESSIONELE VERPLEEGKUNDIGE EN IN HOE 'N MATE SY DIT NA HAAR BASIESE OPLEIDING VERSTAAN HET

\begin{tabular}{|c|c|c|c|c|c|c|}
\hline $\begin{array}{l}\text { ASPEKTE RAKENDE } \\
\text { PROFESS VERPLEEG- }\end{array}$ & $\begin{array}{l}\text { GEEN } \\
\text { RESP }\end{array}$ & $\begin{array}{r}\text { BESUS } \\
\text { IA }\end{array}$ & $\begin{array}{l}\text { MIN OF } \\
\text { MEER }\end{array}$ & BESLS & TO & TALL \\
\hline & & Get & Getal $\%$ & Coll & $\mathbf{N}$ & $\%$ \\
\hline $\begin{array}{l}\text { Wet ven proties. verpl. } \\
\text { verweg word }\end{array}$ & 3 & ${ }^{238} 61.3$ & ${ }^{143} 30.0$ & 1.8 & 388 & 100 \\
\hline $\begin{array}{l}\text { Annopreaklikheid en dis } \\
\text { implikesies deaman }\end{array}$ & 1 & ${ }^{211} 34.1$ & ${ }^{124} \mathrm{s1.8}$ & 5514.1 & 300 & 100 \\
\hline Onathanklike tunkeie & 4 & 180 & 132 & 75 & $\mathbf{3 8 7}$ & 100 \\
\hline $\begin{array}{l}\text { Praktykbettak van } \\
\text { ander kategories }\end{array}$ & 5 & $111_{28.7}^{46.5}$ & $184_{47.7}^{34.1}$ & $91 \stackrel{19.4}{23.6}$ & 388 & 100 \\
\hline
\end{tabular}

op skool gehad het nie, of wat dit wel gehad het maar nie uit eie keuse nie, plans 'n groter verantwoordelikheid op die skowers van die dosent op voor-en na-registrasievlak ten einde die studente te oortuig van die noodsaaklikheid van kennis van verpleging as professie se verlede. Enige professic se geskiedenis is noodsaaklik en verpleging is hier geen uitsondering nie.

\section{AFDELING 2: Basiese opleiding}

Die sanbieding van die vak Etos op basiese vlak geskied hoofsuaklik deur die formele lesingmetode. Min onderrig word in die verpleegfilosofie en verpleegteoriet gegee. Die meeste respondente het aangedui dat die onderrig in Elos in die cerste janr angebied is en wel deur die formele lesing metode. Die aannames or die bestaan van leemtes in die basiese onderrig in die vak Etos en die gebrek an onderskraging van die student wat nie geskiodenis op skool gehad het nie, is beam (Tabel 2)

Die respondente was die positiefste ten opsigte van professionele praktyk en etiek terwyl verpleeggeskiedenis, -teoriet en -filosofie minder gunstig ervane is (Figuur 1). Hierdie gevolgtrekking beasm in ' $n$ mate die aanname dat daar negatiewe persepsies oor die vak Etos bestaan.

\section{AFDELING 3: Studies by Unisa}

Die vermoede dat die stelsel van afstandonderrig vir die Unisastudent om verskeie rodes ' $n$ bron van kommer en angs is, is met hierdie studie bevestig. Die moeste respondente het ' $n$ ander metode bo afstandsonderrig verkies. Die gebrek an kontak met die dosent en ander studente en isolasie van die Unisastudente kan moontlik 'n bron van onsekerheid, kommer en angs wees. Die navorser se aanname dat censasmheid die prominenste emosic sou wees is egter nie bevestig nie (Figur 2).

\section{AFDELING 4: Professionele status}

By hierdie afdeling van die studie is daar ambivalensie angetref ten opsigte van die geregistreerde verpleegkundige se regte. Alhoewel $58.9 \%$ van die respondente beslis of in ' $n$ mate samgestem het dat ' $n$ verpleegkundige rie godwing mag word om teen han sin of kennisvlak op te tree nie, het $61.9 \%$ van die respondente byvoorbeeld in ' $n$ mate nie sanmgertem of bealis nie anamgestem met die stelling dat sy volgens har cie morele waardes moet optree en nie volgens die pasient se versocke of eise nie. "They [health professionals] are not merely automatons programmed to carry out the wishes of others. They are moral agents who are accountable for

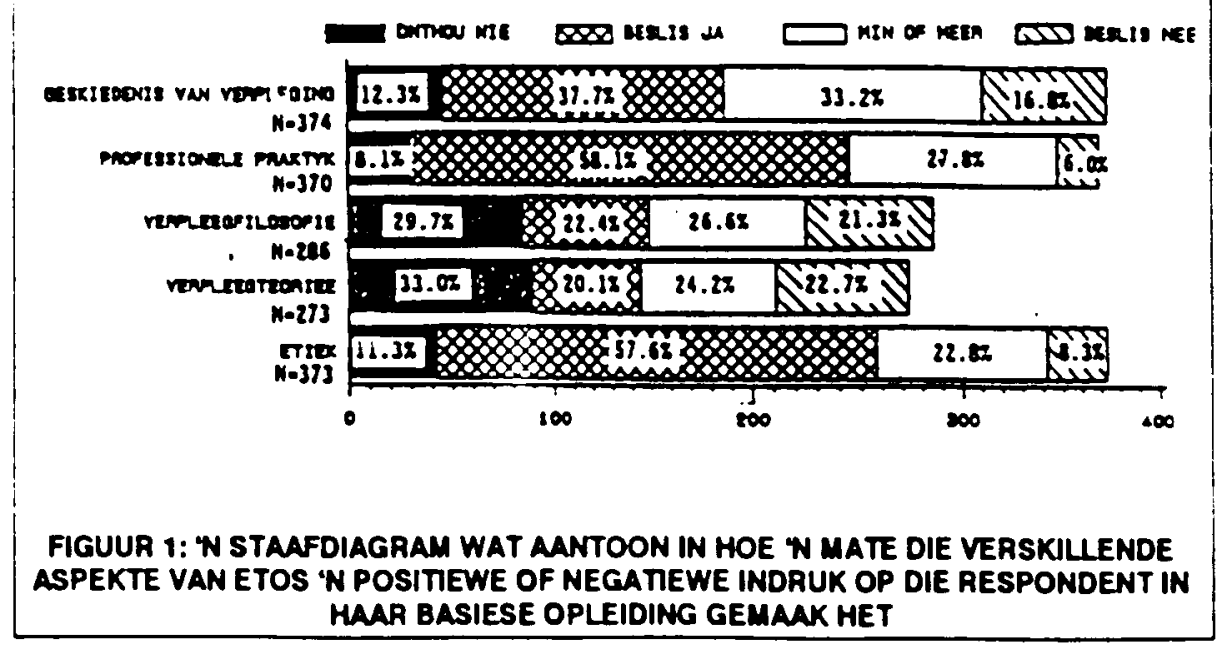




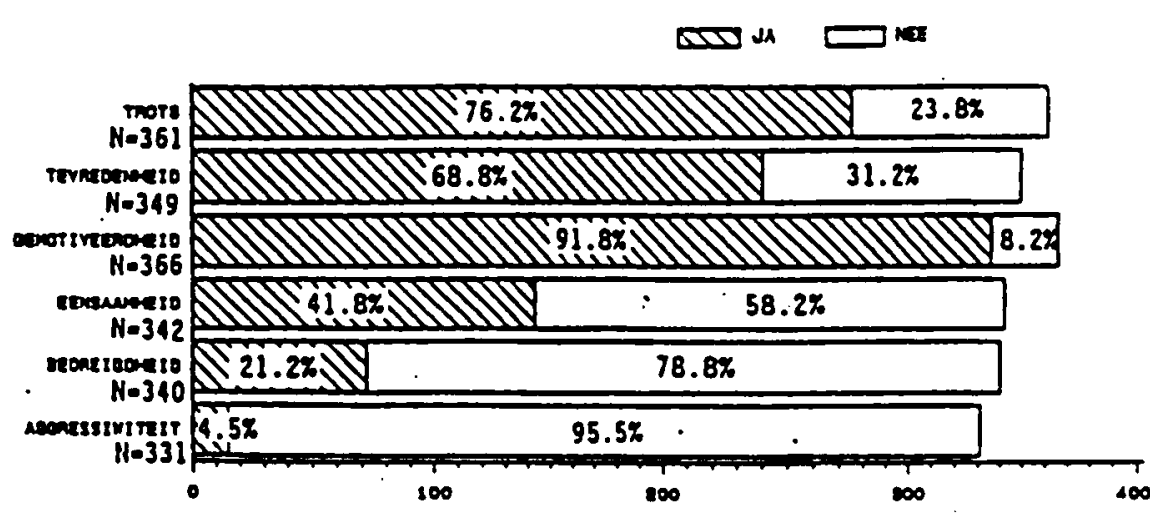

FIGUUR 2: 'N STAAFDIAGRAM MET W AMNDUIDING VAN DIE EMOSIES WAT DIE RESPONDENT ERVAAR MET BETREKKING TOT AFSTANDSONDERRIG

their own actions....." (Curtin \& Flaherty 1982: 90).

Wat die verpleegkundige ae regte ten opsigte van die geneesheer betref is gevind dat die meerderheid respondente $(79 \%)$ wel saamgestem het dat ' $n$ verpleegkundige haar opinie mag lug indien sy nie met die geneesheer saamstem nie of mag weier om ' $n$ voorskrif wit te voer in 20 'n geval. Slegs $25.9 \%$ van die respondente het egter weer gevoel dat die verpleegkundige as voorspraak vir die pasient mag optree indien sy bewus is van onetiese handelinge of ingrepe wat deur die geneesheer beplan word nie.

' $n$ Tendens wat in hierdie studie na vore gekom het is die siening van respondente dat wetenskaplike realiteite sorgsaamheid moet vervang. Slegs $21 \%$ van die respondente het beslis nie met hierdie stelling saamgestem nie. Dit dui op 'n gebrek ten opsigte van die sorgsaamheidskontinuum in verpleging. By die analisering ven die items wat betrekking gehad het op die professionele praktisyn as rolmodel, is aangetoon dat $57.3 \%$ van die respondente van mening was dat ' $n$ professionele verplegkundige nie te alle tye as rolmodel in die praktyk kan optree nie.

Verder is daar in hierdie navorsing bewyse gevind dat daar nie voldoende onderrig in Etos an die basiese student gegee word nie. Die meerderheid respondente $(84 \%)$ is van mening dat die aanbieding van Etos op na-registrasievlak hulle beter voorberei vir die rol as professionele praktisyn

\section{AFDELING 5: Eise wat die professie stel}

Soos sovele ander navorsingsprojekte al bewys het, het hierdie studie dit ook bevestig dat die meerderheid geregistreerde verpleegkundiges byvoorbeeld nie deelneem an die aktiwiteite van hulle professionele verenigings nie. Slegs $47 \%$ van die respondente het aangetoon dat hulle wel vergaderings bywoon en $23 \%$ van die respondente wat wel vergaderings bywoon, het angetoon dat hulle nie baat vind by die vergaderings nie. Waar die respondente moes antoon op watter professionele tydskrifte hulle ingeteken is indien enige, is 'Verpleegnuus' ook gelys.

\section{AFDELING 6: Blografiese agtergrond}

Die studente het bewys dat die Etos-student aan Unisa ' $n$ jonger student as 'n dekade gelede is en dat hulle nie swakker as die over student presteer nie. Hulle behas inteendeel hoer punte. Daar is ook bevind dat die meerderheid respondente in verskillende hoedanighede in hospitale werksaam is.

\section{PRAKTIESE IMPLIKASIES VIR DIE AANBIEDING VAN DIE VAK ETOS}

\section{IMPLIKASIES VIR DIE UNISA-DOSENT}

Die dosent moet andag gee aan:

- die belang van aanbevole literatuur ten einde 'n breer perspektief oor aspekte rakende Etos te verksy

- die belang van voldoende konstruktiewe kommentaar by die evaluering van werkopdragte

- die feil dal die basiese verpleegstudent onvoldoende onderng in verpleegteoriec en verpleegfilosofie gehad het

- die feit dat die meerderheid respondente voel dat sorgsaamheid moet plek maak vir wetenskaplike realiteit

- 'n algemene orienteringsprogram deur middel van klankkassette vir die eerstejasrstudent
IMPLIKASIES VIR DIE DOSENT OP BASIESE VLAK

Die dosent moet andag gee ann:

- die noodsaaklikheid om die jong adolessent op ' $n$ positiewe wyse bekend te stel an die verakillende aspekte vervat in Etos 2003 profeasionele praktyk, etiek, geskiedenis van verpleging, verpleegteoriet en verpleegfilosofie

- die jas van opleiding waarin die studente onderrig in hierdie aspekte ontvang, met inagneming van die geieidelike groei en rypwordings proses van die jong student ten opsigte van haar rolverwagting as in professionele praktisyn

- gereelde kurrikulum hersiening en moontlike innovasie

- moontlike verspreiding van die inhoud deur middel van modules wat deel uitmank van fundamentele verplocgkunde

- die onderrigmetodes wat gebruik word om hierdie inligting oor te dra

- die feit dat daar angedui word dat sorgsamheid plek moet maak vir wetenskaplike realiteite

\section{AANBEVRLINGS VIR VERDERE NAVORSING}

\section{Daar word anbeveel dat:}

- 'n coortgelyke atudie op finalejear basiese studente gedoen word om hul persepsie van Etos te identifiseer

- kwalitatiewe navorsing op die Unisa-student se persepsic van Etos gedoen word en die bevindings met hierdie navorsing vergelyk word

- daar by die eelektering van 'n area vir verdere navorsing respondente in Transvaal gebruik word aangesien die meeste studente volgens hierdic studic se bevindings hul opleiding in Transvaal ontrang het

- daar ' $n$ studie op basiese vlak gedoen word cor die kurrikulum van Etos met spesiale verwysing na onderrigmetodes.

- daar navorsing gedoen word oor die moontlikheid om Etos as ' $n$ verpligte deel van die kurrikulum te maak by alle opleidingsfasilitieite waar verpleegdosente opgelei word soos tans die geval is by Unisa

\section{SAMEVATTING}

Etos-studente het 'n positiewe houding teenoor die vak asook Unisa in die geheel. Die inhoud van die vak kan soveel meer beteken as die student se basiese grondslag van die vak op stewige fondamente gelé word tydens haar 
basiese opleiding. Hiervoor is ' $n$ dosent nodig wat nie net goed onderleg is in die vak Etos nie, maar wat die noodsaaklikheid van die vak vir die opleiding van professionele praktisyns heelhartig steun. Daar kan na dese nie moer oor die bestaansreg van Etos as deel van enige verpleegkurrikulum getwyfel word nie.

\section{BRONNELYS}

Brink, P.J. \& Wood, M.J. (1988). Basic steps in planning nursing research: from question to proposal. 3rd edition. Boston, MA: Jones \& Bartlett.

Brink, H.I.L. (1991). Quantitative vs qualitative research. Nursing $R S A$ Verpleging 6,1: 14-18

Chaska, N.L. (1990). The nursing profession turning points. St. Louis, MO: Mosby.
Curtin, L. \& Flaberty, J.M. (1982). Nursing ethics, theories and pragmatics. Englewood Cliffs: Prentice-Hall

Kirstein, H. (1991). Geselekteerde na-basiese verpleegstudente se persepsies van die vak etos van verpleging. MA. Cur - verhandeling. Unisa.

Mashaba, T.G. (1986). The significance of secondary school education for education and training of nurses in South Africa. Journal of Advanced Nursing II 4 : 395-401.

Mouton, J. \& Marais, H.C. (1989). Metodologie van die geesteswetenskappe: basiese begrippe. Pretoria: Raad vir Geesteswetenskaplike Navorsing.

Quinn, C.A. \& Smith, M.D. (1987). The professional commitment: issues and ethics in nursing. Philadelphia: Saunders
Seaman, C.H.C. (1987). Research methods: principles, practice and theories for mursing. 3rd edition. Norwalk, CT: Appleton \& Lange

Searle, C. (1987). Professonele praktyk: in Suid-Afrikaanse verpleegperspektief. Durban: Butterworths

Treece, E.W. Treece, J.W. (1986). Elements of research in mursing. 4th odition. St. Louis, MO: Mosby.

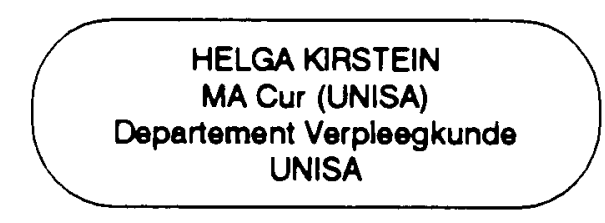

